\title{
LOW DIGIT RATIO (2D:4D) AND MASCULINE ATTRIBUTES: A CRITICAL ANALYSIS
}

\author{
Muhammad Shahidul Islam *1凶, Prof. Brajanath Kundu ${ }^{2}$ \\ ${ }^{* 1}$ Research Scholar, Department of Physical Education and Sport Science, Visva-Bharati University, \\ West Bengal, India \\ ${ }^{2}$ Professor, Department of Physical Education and Sport Science, Visva-Bharati University, West \\ Bengal, India
}

DOI: https://doi.org/10.29121/granthaalayah.v8.i7.2020.773

Article Type: Research Article

Article Citation: Muhammad Shahidul Islam, and Prof. Brajanath Kundu. (2020). LOW DIGIT RATIO (2D:4D) AND MASCULINE ATTRIBUTES: A CRITICAL ANALYSIS. International Journal of Research -GRANTHAALAYAH, 8(7), 384-390.

https://doi.org/10.29121/granthaa layah.v8.i7.2020.773

Received Date: 15 July 2020

Accepted Date: 31 July 2020

\section{Keywords:}

Digit Ratio

Sporting Ability

Prenatal Testosterone

Ring Finger

Index Finger

Hormone

Masculinity

\section{ABSTRACT}

Background: The ratio between the length of the index finger (2D) concerning the length of the ring finger (4D) of a palm, which is noticed as second to fourth digit ratio (2D:4D). However, the length ratio of the second digit (the index finger) to that of the fourth digit (the ring finger) probably shows the quantity of male hormone, to which an individual is exposed in the womb of the mother. Likewise, several investigations define that low second to fourth digit finger ratio tended to have related to prenatal testosterone hormone. Prenatal testosterone hormone masculinizes the human body and therefore may build the athletic body.

Aim: To review scientific literature related to the lower ratio of second to fourth digit ratio and masculinity.

Methods: The Researcher collected scientific evidence through electronic databases; PubMed, Medline, Google Scholar, Google Advanced Search, Web of Science, and critically analyzed the entire relevant article according to the nature of this study.

Findings: The lower second to fourth digit ratio is associated with prenatal testosterone hormone and is also related to masculine traits that may help in sporting performance.

Conclusion: Masculine attributes may be linked to a lower digit finger ratio (2D:4D).

\section{INTRODUCTION}

Second to fourth digit ratio (2D:4D) at the end of the first trimester of pregnancy (from week 1 to the end of week 12 of the pregnancy) is believed to be a biomarker of the balance between prenatal testosterone and prenatal estrogen hormone (Manning et al., 2014; Garn et al., 1975; Manning et al., 1998). There-after, the digit ratio (2D:4D) probably remain unchanged throughout life (Manning et al., 1998). However, Manning (2002) indicated that the digit ratio (2D:4D) was set particularly between weeks 8 and 12 at the end of the first trimester. The male fetuses produce large quantities of testosterone hormone, primarily from their testis. This influences the brain and other organ systems development. Generally in females the length of both fingers (index and ring finger) is usually about equal (digit ratio $=1.00$ ), whereas in males the ring finger is usually slightly longer (digit ratio $=0.98$ ): a tiny difference in sex (Manning, 2002).

(C) 2020 The Author(s). This is an open access article distributed under the terms of the Creative Commons Attribution License, which permits unrestricted use, distribution, and reproduction in any medium, provided the original author and source are credited. 
During the gestation period, the ring fingers serve as a larger number of receptors for testosterone hormone. The ratio of index finger length (2D) to a palm's ring finger length (4D) is known as a digit finger ratio (2D:4D). The length ratio of the second digit (the index finger) to the fourth digit (the ring finger) illustrates the number of male hormones, primarily testosterone that a person is exposed to in the mother's womb (Manning et al., 2007; Fink et al., 2003; Fink et al., 2004). The 2D:4D Digit ratio is sexually dimorphic: while the second digit (index finger) is typically shorter for men, and the length difference between the two digits is higher for men than for women (Manning et al., 2007; Manning et al., 2014) Testosterone influences the growth of the ring finger (4D), whereas estrogen exposure stimulates the growth of the index finger (2D). Specifically, males demonstrated a lower ratio, due to increased prenatal testosterone exposure (Manning, 2002). Presumably, this increased prenatal testosterone exposure may promotes the various sports performance. It was shown that the lower digit ratio (high prenatal androgens) indicates the sporting performance of soccer, surfing, sprinting, endurance, hand-grip strength, rowing, kabaddi, swimming, tennis, etc. (Manning et al., 2007; Manning \& Taylor, 2001; Islam \& Kundu, 2019; Manning \& Hill, 2009; Hone \& McCullough, 2012; Longman et al., 2011; Sudhakar et al., 2014; Sudhakar et al., 2013; Hsu et al., 2015; Kim \& Kim, 2016; Islam \& Kundu, 2020).

Several studies portray the low second to fourth digit finger ratio in which prenatal testosterone hormone was associated with masculine traits. They also recommend that the ratio of 2D:4D is a feasible indicator for sports success rate.

\section{AIM OF THE STUDY}

The specific aim of this critical review study was to explore the relationship between digit ratio (2D:4D) and masculine attributes.

\section{Intrauterine Structure May Be Noticed by Finger Lengths}

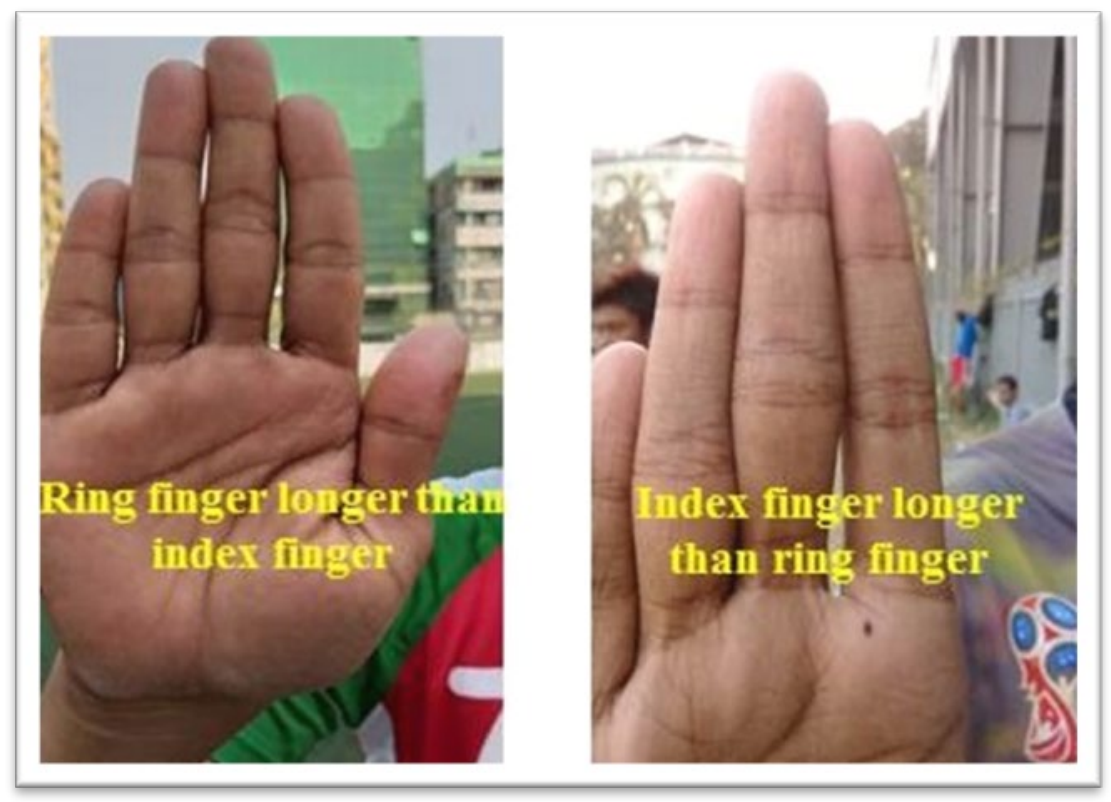

Figure 1: different intrauterine structure may be define by finger lengths (2D and 4D)

According to Figure-1, palm to the left, quite a notable side where the ring finger is about one centimeter longer than the index finger, this ring finger is a possible indication of prenatal testosterone before birth and index finger does not offer the same line. Palm to the right side the index finger is about one centimeter longer than the ring finger that shows the feminine prone hand in male. 


\section{METHODS}

Acquisition of Evidence: In this systematic review study a thorough online searching procedure was applied for acquisition of evidence. The electronic databases: PubMed, Medline, Google Scholar, Google Advanced Search, and Web of Science were carefully searched to review the literature.

Inclusion and Exclusion Criteria: Studies related to the objective of this paper were included in this study whereas studies that were not directly matched with the concept of analysis were excluded from the process. Inclusion criteria were included with the areas of digit ratio (2D:4D), prenatal testosterone hormone, prenatal androgen, prenatal estrogen hormone, athletic ability, visual-spatial ability, decision-making capacity, aggression, sports performance, and Sexual orientation.

Selection Procedure of Review Articles: In the first attempt, a total of 93 articles with full text were assessed based on eligibility criteria. Out of which only 46 papers were fulfilled the objective of this study. Searches were limited to the years 1975 to 2020 . The final database searches were conducted in 17th July 2020 . Eligibility of articles was assessed based on eligibility criteria first at the level of the title, abstract, source and then the full text article.

\section{LOW DIGIT RATIO AS DETERMINANTS OF MASCULINE ATTRIBUTES}

Professor John Manning has published numerous research papers showing associations between 2D:4D ratio and enhanced sporting performance. The lower the 2D:4D ratio gets, the higher the physical ability continues to improve. Sports containing balls include the ability to make fast visual-spatial judgments as to where a ball will land; Manning found people with lower 2D:4D ratios do better on visual-spatial skill tests. He theorizes that prenatal testosterone exposure stimulates the central nervous system to strengthen the ability to make certain visual-spatial decisions (Manning, 2002; Manning \& Taylor, 2001; Brett, 2016). Previous studies have shown that men and women with higher, more feminized 2D:4D ratios have a greater risk of developing depression and anxiety compared with those with lower, more masculine 2D:4D ratios (Bailey \& Hurd, 2005). Similarly, a notable study indicate that high prenatal testosterone levels help to 'organize' male facial features to subsequently represent dominance (Figure-2) and presumably activated masculine characteristics during puberty (Neave et al., 2003).

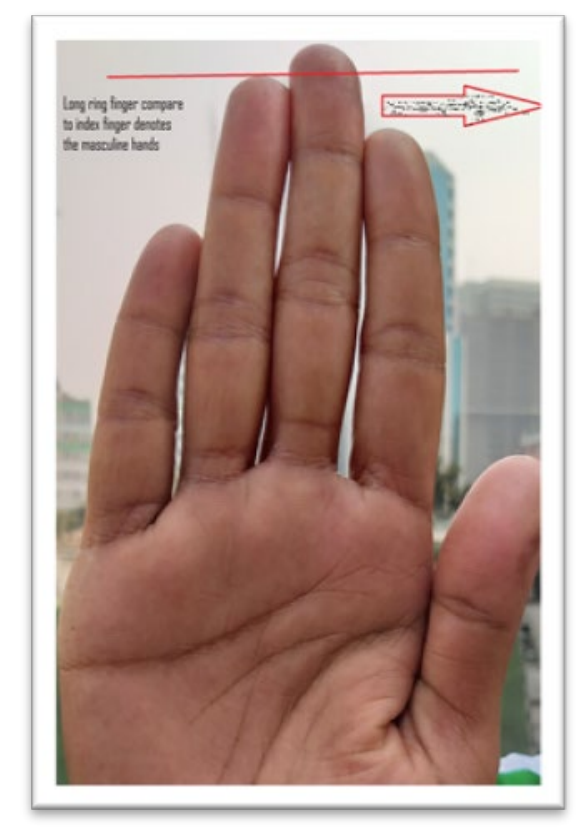

Figure 2: Masculinized hand (long 4D compare to 2D) represent the dominance behavior

\section{DIGIT RATIO LINKED WITH AGGRESSIVE BEHAVIOR}

According to evaluate the findings of a study's questionnaire, men reveal higher levels of computer task aggression compared with women. There was a negative association between 2D:4D and aggression in males but 
not in females (Kuepper \& Hennig, 2007). Likewise, researchers Valentina Perciavalle and his team analyzed elevated testosterone rates throughout embryonic life, testifying to a small second-to-fourth digit ratio (2D:4D), as well as in adulthood concerning professional soccer players' aggressive behaviors. There was a strong negative link between the Sal/T and the 2D:4D ratio, as well as the 2D:4D ratio and player aggressiveness. Eventually, the study showed that offensive activity in professional soccer players, with the consequent increased risk of fouls during the game, is more likely to occur in players with elevated testosterone levels, not just in adulthood but also during their prenatal lives (Perciavalle et al., 2013). It is also believed that the digit ratio is a reasonable measure of adult steroid hormones due to its association with fetal steroid hormones. Nevertheless, experience more noticeable testosterone surges in demanding conditions such as those faced in professional sport. Low-digit ratio in males also tends to be more aggressive and take more risks in their life (Tomkinson \& Dyer, 2017).

\section{2D:4D AND SEXUAL ORIENTATION}

Previous researchers examined the relationship between 2D:4D digit ratio and sexual orientation in Chinese men and studied the influences of the components used to determine sexual orientation. The study revealed that left 2D:4D had a significant positive correlation with sexual identity, sexual desire, sexual conduct and right 2D:4D had a significant positive correlation with sexual attraction (Xu \& Zheng, 2016). Similarly, prenatal testosterone and estrogen hormone is likely to be connected with males' sexual orientation (Lippa, 2003). The heterosexual males had lower 2D:4D than non-heterosexual males in several previous studies, which highlight the fact that nonheterosexual males experience higher rates of androgen in utero than population norms (Kangassalo et al., 2011). Other researchers noted that, in Austrian homosexual and heterosexual males, this means 2D:4D. They found no major difference between 2D:4D homosexual and heterosexual mean, with values falling from 0.96 to 0.97 for both (Voracek et al., 2005).

\section{DIGIT RATIO ENDORSE COGNITIVE DIMENSION}

Digit ratio is a putative measure of the differences in sports success (Golby \& Meggs, 2011). An analysis of several sport-related psychological variables (mental toughness, aggression, optimism scale, coping mechanisms, and aim orientations) with a masculine digit ratio showed high scores of positive disposition than those with a feminine digit ratio. The study also argues the mental resilience decided partly during the gestation period (Golby \& Meggs, 2011) that benefited for gender, age, and sporting experience (Nicholls et al., 2009). The visual-spatial intelligence can be assessed by mental rotation score test (Vandenberg \& Kuse, 1978; Guillot et al., 2007; Neubauer et al., 2010; Vandenberg \& Kuse, 1978). High exposure to prenatal testosterone is likely to be linked to handedness (Lust et al., 2011; Coren, 1998). Left-handed people dominated by the right hemisphere and assists visual-spatial ability (Geschwind \& Galaburda, 1985). Interestingly, sensitivity to androgenization more impacts the right palm than the left palm (Brown et al., 2002; McFadden \& Shubel, 2002; Williams et al., 2000). There is also a significant correlation between the right palm digit ratio and some psychological and behavioral characteristics relative to the left palm digit ratio (Williams et al., 2000). So, the findings proved that the low digit ratio has an organizational benefit in the cognitive dimension.

\section{CONCLUSION}

Testosterone has anabolic (protein tissue building) features of medicinal value and these steroids are used by athletes to build muscle mass, decrease fat, and improve performance (Mazur \& Booth, 1998). High prenatal testosterone hormone established on the mother's womb and this remains unchanged throughout life (Manning et al., 1998). Manning et al., (2017) stated that prenatal sex steroids may have an effect on "male" occupations, with higher androgenization rates that are low-digit ratio, resulting in "male" occupational preference and higher selfrated masculinity. So, these hormonal traits maybe influenced on masculine attributes. To summarize this review study showed that there may be a relationship between second to fourth digit ratio (2D:4D) and masculine attributes. Low second to fourth digit ratio (2D:4D) can be an indicator in scouting potential athletes. Besides, we thought sporting success might be in our hands. For all counts, and with proven findings, it is no wonder that low digit ratio has an "organizational effect" on adult males and females that is likely to be beneficial in working hard. 
Low Digit Ratio (2d:4d) And Masculine Attributes: A Critical Analysis

\section{RECOMMENDATION}

Low digit ratio (2D:4D) shows the tentative marker for masculinity. So, the lower 2D:4D may be a helpful pointer for competitive sports.

\section{SOURCES OF FUNDING}

This research received no specific grant from any funding agency in the public, commercial, or not-for-profit sectors.

\section{CONFLICT OF INTEREST}

The author have declared that no competing interests exist.

\section{ACKNOWLEDGMENT}

None.

\section{REFERENCES}

[1] Bailey, A. A., \& Hurd, P. L. (2005). Depression in men is associated with more feminine finger length ratios. Personality and Individual Differences, 39(4), 829-836. https://doi.org/10.1016/j.paid.2004.12.017

[2] Brett. (2016, July 25). 2D:4D Ratio, Testosterone, and Masculinity. The Art of Manliness. https://www.artofmanliness.com/articles/2d4d-ratio-masculinity/

[3] Brown, W. M., Hines, M., Fane, B. A., \& Breedlove, S. M. (2002). Masculinized finger length patterns in human males and females with congenital adrenal hyperplasia. Hormones and Behavior, 42(4), 380-386. https://doi.org/10.1006/hbeh.2002.1830

[4] Coren, S. (1998). Prenatal testosterone exposure, left-handedness, and high school delinquency. Behavioral and Brain Sciences - BEHAV BRAIN SCI, 21, 369-370. https://doi.org/10.1017/S0140525X98321226

[5] Fink, B., Neave, N., \& Manning, J. T. (2003). Second to fourth digit ratio, body mass index, waist-to-hip ratio, and waist-to-chest ratio: Their relationships in heterosexual men and women. Annals of Human Biology, 30(6), 728-738. https://doi.org/10.1080/03014460310001620153

[6] Fink, Bernhard, Manning, J. T., \& Neave, N. (2004). Second to fourth digit ratio and the 'big five' personality factors. Personality and Individual Differences, 37(3), 495-503. https://doi.org/10.1016/j.paid.2003.09.018

[7] Garn, S. M., Burdi, A. R., Babler, W. J., \& Stinson, S. (1975). Early prenatal attainment of adult metacarpalphalangeal rankings and proportions. American Journal of Physical Anthropology, 43(3), 327-332. https://doi.org/10.1002/ajpa.1330430305

[8] Geschwind, N., \& Galaburda, A. M. (1985). Cerebral lateralization. Biological mechanisms, associations, and pathology: I. A hypothesis and a program for research. Archives of Neurology, 42(5), 428-459.

[9] Golby, J., \& Meggs, J. (2011). Exploring the organizational effect of prenatal testosterone upon the sporting brain. Journal of Sports Science \& Medicine, 10(3), 445-451.

[10] Guillot, A., Champely, S., Batier, C., Thiriet, P., \& Collet, C. (2007). Relationship Between Spatial Abilities, Mental Rotation and Functional Anatomy Learning. Advances in Health Sciences Education, 12(4), 491-507. https://doi.org/10.1007/s10459-006-9021-7

[11] Hone, L. S. E., \& McCullough, M. E. (2012). 2D:4D ratios predict hand grip strength (but not hand grip endurance) in men (but not in women). Evolution and Human Behavior, 33(6), 780-789. https://doi.org/10.1016/j.evolhumbehav.2012.07.003

[12] Hsu, C.-C., Su, B., Kan, N.-W., Lai, S.-L., Fong, T.-H., Chi, C.-P., Chang, C.-C., \& Hsu, M.-C. (2015). Elite collegiate tennis athletes have lower 2D: 4D ratios than those of nonathlete controls. Journal of Strength and Conditioning Research, 29(3), 822-825. https://doi.org/10.1519/JSC.0000000000000681

[13] Islam, M. S., \& Kundu, B. (2019). Digit ratio and soccer. Orthopedics and Sports Medicine: Open Access Journal, 3(1), 227-230. https://doi.org/10.32474/OSMOAJ.2019.03.000154 
Muhammad Shahidul Islam, and Prof. Brajanath Kundu

[14] Islam, M. S., \& Kundu, B. (2020). Soccer Passing Accuracy Differentiates Between High and Low Digit Ratio (2D:4D) Soccer Players. American Journal of Sports Science, 8(3), 49-55. https://doi.org/10.11648/j.ajss.20200803.11

[15] Kangassalo, K., Pölkki, M., \& Rantala, M. J. (2011). Prenatal Influences on Sexual Orientation: Digit Ratio (2D:4D) and Number of Older Siblings: Evolutionary Psychology. https://doi.org/10.1177/147470491100900402

[16] Kim, T. B., \& Kim, K. H. (2016). Why is digit ratio correlated to sports performance? Journal of Exercise Rehabilitation, 12(6), 515-519. https://doi.org/10.12965/jer.1632862.431

[17] Kuepper, Y., \& Hennig, J. (2007). Behavioral aggression is associated with the 2D:4D ratio in men but not in women. Journal of Individual Differences, 28(2), 64-72. https://doi.org/10.1027/1614-0001.28.2.64

[18] Lippa, R. A. (2003). Are 2D:4D finger-length ratios related to sexual orientation? Yes for men, no for women. Journal of Personality and Social Psychology, 85(1), 179-188. https://doi.org/10.1037/0022-3514.85.1.179

[19] Longman, D., Stock, J. T., \& Wells, J. C. K. (2011). Digit ratio (2D:4D) and rowing ergometer performance in males and females. American Journal of Physical Anthropology, 144(3), 337-341. https://doi.org/10.1002/ajpa.21407

[20] Lust, J. M., Geuze, R. H., Van de Beek, C., Cohen-Kettenis, P. T., Bouma, A., \& Groothuis, T. G. G. (2011). Differential effects of prenatal testosterone on lateralization of handedness and language. Neuropsychology, 25(5), 581-589. https://doi.org/10.1037/a0023293

[21] Manning, J., Kilduff, L., Cook, C., Crewther, B., \& Fink, B. (2014). Digit Ratio (2D:4D): A Biomarker for Prenatal Sex Steroids and Adult Sex Steroids in Challenge Situations. Frontiers in Endocrinology, 5. https://doi.org/10.3389/fendo.2014.00009

[22] Manning, J. T., \& Hill, M. R. (2009). Digit ratio (2D:4D) and sprinting speed in boys. American Journal of Human Biology: The Official Journal of the Human Biology Council, 21(2), 210-213. https://doi.org/10.1002/ajhb.20855

[23] Manning, J. T., Scutt, D., Wilson, J., \& Lewis-Jones, D. I. (1998). The ratio of 2nd to 4th digit length: A predictor of sperm numbers and concentrations of testosterone, luteinizing hormone and oestrogen. Human Reproduction (Oxford, England), 13(11), 3000-3004. https://doi.org/10.1093/humrep/13.11.3000

[24] Manning, J. T., \& Taylor, R. P. (2001). Second to fourth digit ratio and male ability in sport: Implications for sexual selection in humans. Evolution and Human Behavior: Official Journal of the Human Behavior and Evolution Society, 22(1), 61-69.

[25] Manning, John T. (2002). Digit Ratio (A pointer to Fertility, Behavior, and Health). Rutgers University Press.

[26] Manning, John T., Churchill, A. J. G., \& Peters, M. (2007). The effects of sex, ethnicity, and sexual orientation on self-measured digit ratio (2D:4D). Archives of Sexual Behavior, 36(2), 223-233. https://doi.org/10.1007/s10508-007-9171-6

[27] Manning, J. T., Trivers, R., \& Fink, B. (2017). Is Digit Ratio (2D:4D) Related to Masculinity and Femininity? Evidence from the BBC Internet Study. Evolutionary Psychological Science, 3(4), 316-324. https://doi.org/10.1007/s40806-017-0098-4

[28] Mazur, A., \& Booth, A. (1998). Testosterone and dominance in men. The Behavioral and Brain Sciences, 21(3), 353-363; discussion 363-397.

[29] McFadden, D., \& Shubel, E. (2002). Relative lengths of fingers and toes in human males and females. Hormones and Behavior, 42(4), 492-500.

[30] Neave, N., Laing, S., Fink, B., \& Manning, J. T. (2003). Second to fourth digit ratio, testosterone and perceived male dominance. Proceedings of the Royal Society B: Biological Sciences, 270(1529), 2167-2172. https://doi.org/10.1098/rspb.2003.2502

[31] Neubauer, A. C., Bergner, S., \& Schatz, M. (2010). Two- vs. three-dimensional presentation of mental rotation tasks: Sex differences and effects of training on performance and brain activation. Intelligence, 38(5), 529539. https://doi.org/10.1016/j.intell.2010.06.001

[32] Nicholls, A. R., Polman, R. C. J., Levy, A. R., \& Backhouse, S. H. (2009). Mental toughness in sport: Achievement level, gender, age, experience, and sport type differences. Personality and Individual Differences, 47(1), 7375. https://doi.org/10.1016/j.paid.2009.02.006

[33] Perciavalle, V., Di Corrado, D., Petralia, M. C., Gurrisi, L., Massimino, S., \& Coco, M. (2013). The second-to-fourth digit ratio correlates with aggressive behavior in professional soccer players. Molecular Medicine Reports, 7(6), 1733-1738. https://doi.org/10.3892/mmr.2013.1426

International Journal of Research -GRANTHAALAYAH 
[34] Sudhakar, H. H., Veena, U. B., \& Tejaswi, R. N. (2013). Digit ratio (2D:4D) and performance in Indian swimmers. Indian Journal of Physiology and Pharmacology, 57(1), 72-76.

[35] Sudhakar, Honnamachanahalli H., Majumdar, P., Umesh, V., \& Panda, K. (2014). Second to fourth digit ratio is a predictor of sporting ability in elite Indian male Kabaddi players. Asian Journal of Sports Medicine, 5(3). https://doi.org/10.5812/asjsm.23073

[36] Tomkinson, G., \& Dyer, M. (2017). Finger size does matter... in sports. https://theconversation.com/fingersize-does-matter-in-sports-82876

[37] Vandenberg, S. G., \& Kuse, A. R. (1978). Mental rotations, a group test of three-dimensional spatial visualization. Perceptual and Motor Skills, 47(2), 599-604. https://doi.org/10.2466/pms.1978.47.2.599

[38] Voracek, M., Manning, J. T., \& Ponocny, I. (2005). Digit Ratio (2D:4D) in Homosexual and Heterosexual Men from Austria. Archives of Sexual Behavior, 34(3), 335-340. https://doi.org/10.1007/s10508-005-3122-x

[39] Williams, T. J., Pepitone, M. E., Christensen, S. E., Cooke, B. M., Huberman, A. D., Breedlove, N. J., Breedlove, T. J., Jordan, C. L., \& Breedlove, S. M. (2000). Finger-length ratios and sexual orientation. Nature, 404(6777), 455456. https://doi.org/10.1038/35006555

[40] Xu, Y., \& Zheng, Y. (2016). The Relationship Between Digit Ratio (2D:4D) and Sexual Orientation in Men from China. Archives of Sexual Behavior, 45(3), 735-741. https://doi.org/10.1007/s10508-015-0535-z 